\title{
ADAPTAÇÃO PIONEIRA DOS IMIGRANTES DA LETÔNIA NA TERRA PROMETIDA
}

\author{
Henrique M. Silva *
}

Na primeira metade do século XIX, o governo imperial brasileiro expressava pouco interesse em relação à imigração estrangeira. Tal postura advinha, em grande medida, da abundante oferta de mão-de-obra escrava africana, que só se alteraria com a perspectiva do fechamento total do tráfico negreiro no Atlântico.

Até aquele momento, o apoio dado à colonização agrícola européia limitouse a pequenas porções da região meridional do país, para garantir um mínimo de povoamento das áreas fronteiriças. A mudança de atitude somente ocorreu na segunda metade do século XIX, quando a utilização de mão-de-obra imigrante nas plantações de café das províncias do Sudeste se mostrou viável.

Esse processo se deu inicialmente em bases tímidas e experimentais, e somente a partir da abolição da escravatura a imigração subvencionada adquiriu caráter mais expressivo.

Dois modelos distintos de imigração massiva se desenvolveram em terras brasileiras: o primeiro, iniciado por volta de 1820, enfatizava o estabelecimento de colônias, sobretudo no Sul do país, através de pequenas propriedades rurais, em sua maioria subvencionadas pelo Estado; o segundo, vinculado à expansão da cafeicultura, sobretudo da paulista, baseava-se no regime de parcerias, no qual, sob contrato, o fazendeiro subsidiava a vinda e os meios de instalação e manutenção dos colonos até que estes pudessem pagar tais despesas com o produto de suas primeiras colheitas.

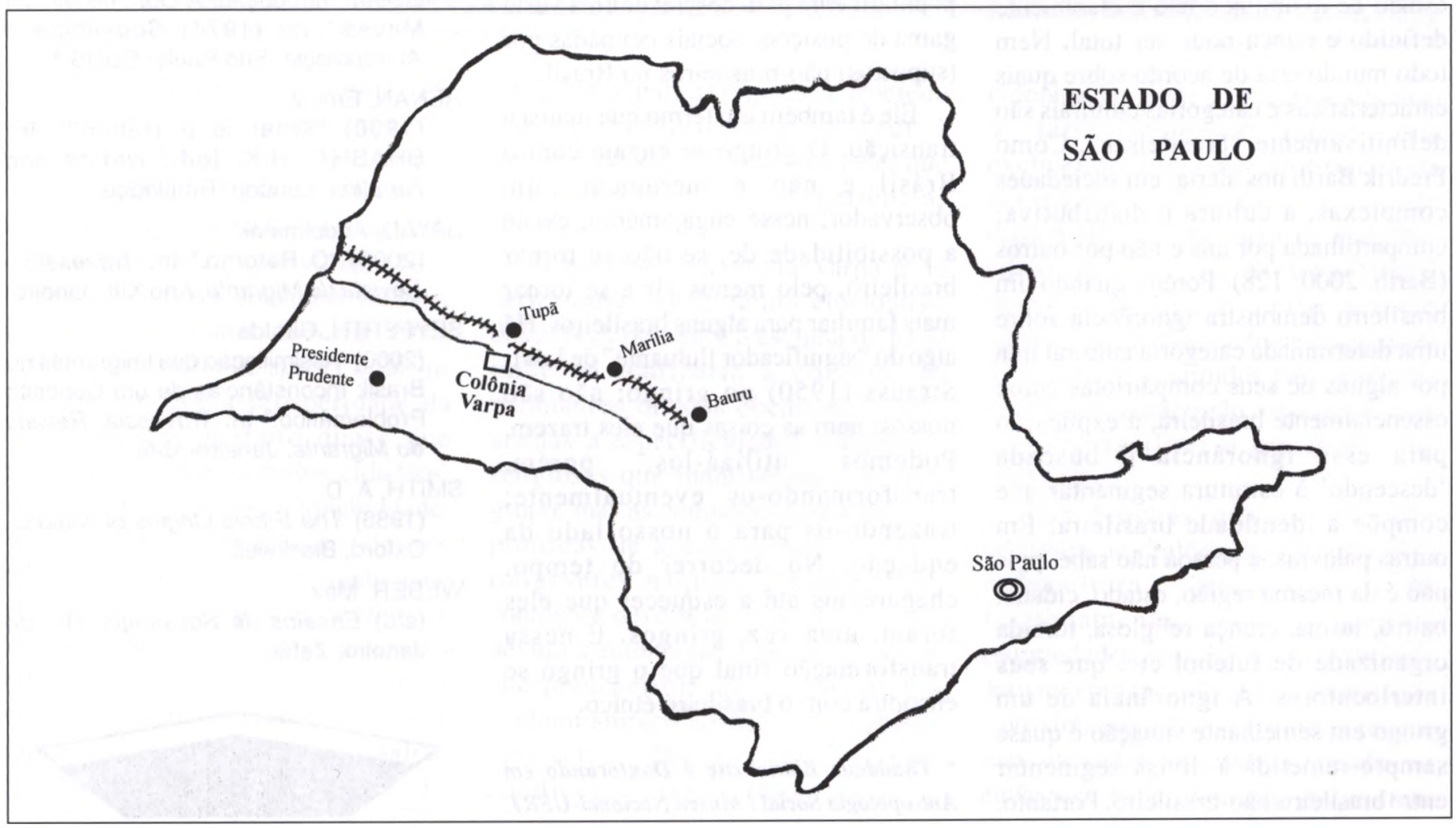


A existência desse modelo limitouse ao curto período de duas décadas, vindo a ser substituído pelo regime do colonato, que consistia em pagamento separado do cultivo e da colheita e não mais por rendimento, como na forma anterior. Nesta nova forma de contrato, a imigração passava a ser subvencionada exclusivamente pelos governos estaduais e federal.

Embora as colônias agrícolas de imigrantes europeus tenham marcado profundamente a evolução e a identidade das províncias do Sul do país, elas também se fizeram presentes, ainda que em proporção menor, em São Paulo, Rio de Janeiro e Espírito Santo, e tiveram papel importante na evolução social, econômica e política das regiões onde foram inseridas. Neste artigo enfocaremos uma colonização ocorrida no estado de São Paulo.

\section{OS IMIGRANTES LETOS DA COLÔNIA VARPA}

A presença dos imigrantes Letos em terras brasileiras, não pode ser entendida como uma história da imigração e da colonização no Brasil, nem pela sua expressão numérica nem tampouco pelo seu impacto na vida e nos rumos do processo do qual fez parte. No entanto, sua relevância aparece perceptível quando se analisam as pegadas do cotidiano em que tal experiência se inscreveu. $\mathrm{O}$ processo migratório que envolveu esse grupo decorreu do conturbado cenário político-institucional vivido pela pequena República Báltica da Letônia no início do século $\mathrm{XX}$, no breve período de sua existência enquanto república independente, e também das características culturais que moveram um pequeno contingente de pessoas em busca da terra prometida.

Tais aspectos, colocados perante as contingências do novo meio, forjaram o sentido e a natureza singular dessa colonização ocorrida em pleno sertão paulista, calcada em arranjos coletivos e de ajuda mútua, sobretudo nos primeiros tempos de assentamento na região do curso médio do vale do Rio do Peixe.

A ocupação e a colonização do interior paulista, em razão das suas condicionantes, tiveram efeito devastador sobre o meio ambiente e praticamente se fizeram à custa da eliminação das populações autóctones. De modo geral, esse processo ocorreu a partir do padrão imediatista e predatório que impulsionou o boom econômico da cafeicultura e das culturas adjacentes, que em alguns casos teve duração efêmera.

Algumas cidades que surgiram ao longo da ferrovia, em particular na região da Alta Paulista, onde esta história ocorreu, muito cedo se tornaram cidades-fantasmas, e são de certa forma testemunhas concretas desse processo.

A experiência colonizadora dos imigrantes letos da colônia Varpa pode ser considerada como dissonante do processo geral e da dinâmica expansiva da fronteira paulista dos anos 1920, pois sua motivação se deu em razão das contingências político-institucionais no país de origem e por uma motivação de caráter religioso, através de um movimento ocorrido no interior da Igreja Batista da Letônia denominado “despertamento" (Ronis,1974; Tupes, 1979), no qual se envolveu esse grupo de imigrantes.

Este caráter dissonante do processo geral de colonização que marcou a ocupação da fronteira paulista do início do século XX deve ser entendido na sistemática do assentamento desse grupo naquele sertão, envolvendo formas de organização do trabalho de caráter cooperativo e de ajuda mútua e formas de divisão fundiária mais eqüitativas que, de certo modo, destoavam do padrão predominante no Oeste Paulista.

Tal arranjo baseou-se, na maioria dos casos, na existência de lotes familiares, semelhantes às colônias do Sul do Brasil, e numa porção menor de terras onde se organizou uma comunidade de caráter essencialmente coletivista, denominada "corporação evangélica Palma", composta de aproximadamente 400 pessoas, vivendo numa área de 350 alqueires paulistas.

Esse movimento de transposição transatlântica em direção ao sertão paulista envolveu mais de 2300 pessoas e deve ser compreendido, não apenas no sentido conjuntural (político/ econômico) e religioso, que marcou o processo migratório e influiu em suas tomadas de decisão, mas também, naquilo que denominamos como crença no progresso, fenômeno fundamental que caracterizou a expansão da fronteira no Novo Mundo e a busca de novas oportunidades de vida, corporificadas, neste caso, no esforço de edificação de uma nova sociedade.

Esta perspectiva, para os batistas, no sentido Weberiano, foi condicionada por uma postura de ascetismo religioso, que orientava um comportamento metódico e um planejamento racional de toda a vida do indivíduo de acordo com a vontade de Deus. A pré-condição para esse ascetismo, segundo Weber (1996, p.109), não seria mais um opus supererogationies, mas algo que podia ser requerido de todo aquele que estivesse certo da salvação. $\mathrm{E}$ foi justamente nesse sentido motivador que a natureza dessa colonização imprimiu sua diferença, potencializando uma conduta obstinada de enfrentamento a toda ordem de pressões e obstáculos e um quase inabalável otimismo com relação ao futuro.

De modo similar esse tipo de motivação esteve presente na maioria das comunidades ascéticas, que viam na hinterlândia do Novo Mundo os sinais dos novos tempos, ou a possibilidade de realizar seu designo e professar suas crenças. Tal crença pode ser confirmada no entrecruzamento de muitos 


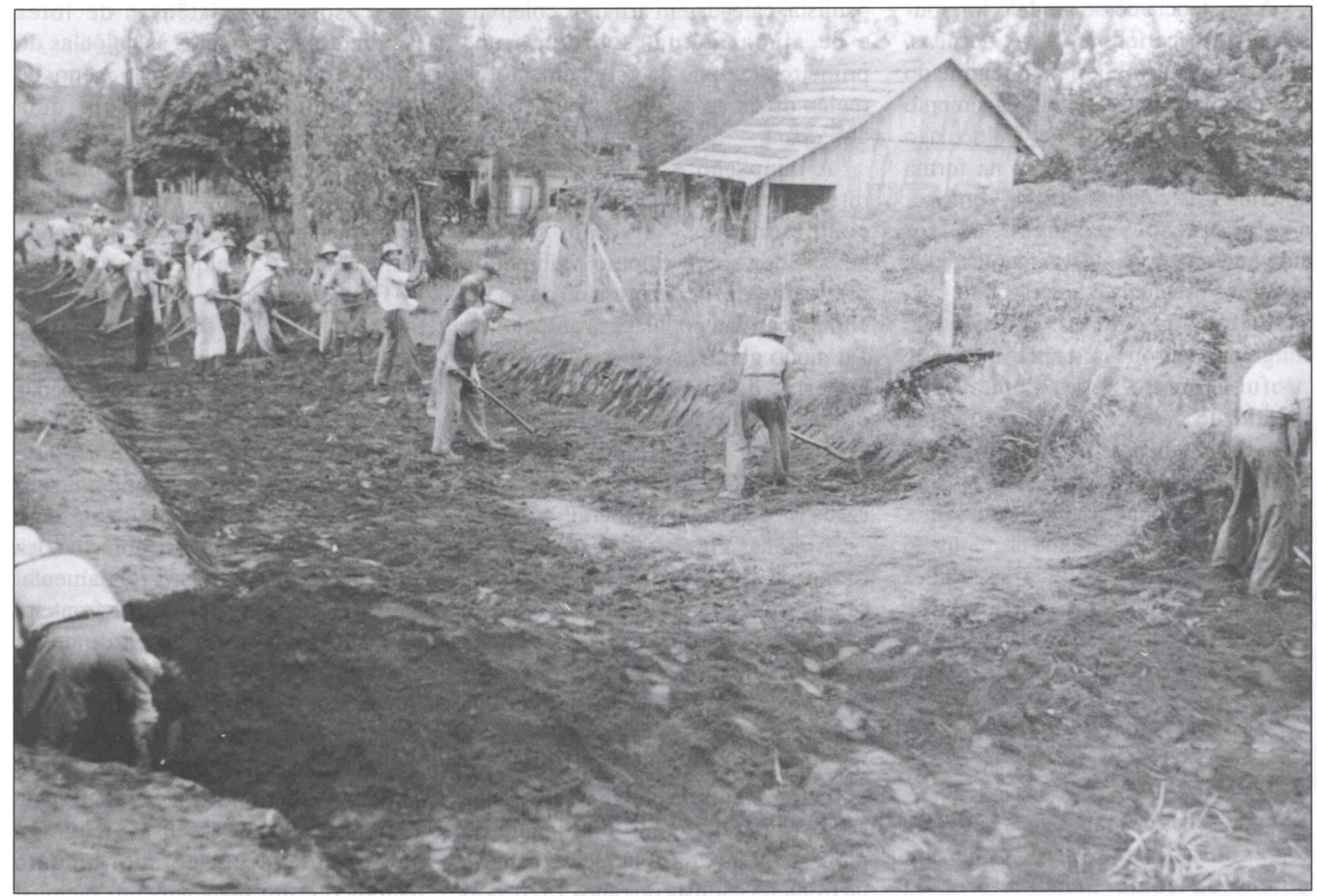

testemunhos de antigos moradores, que expressavam um sentimento modesto de orgulho e de heroísmo em relação ao tempo passado, quando incontáveis histórias e experiências se sucederam.

Não obstante, apesar de essas construções sobre o passado possuírem, nos termos de Bennett \& Kohl (1995, p.160), um sentido de spirits of do-ityourself, em que a prosperidade da localidade era atributo quase que exclusivo dos seus próprios cidadãos, na realidade o sucesso e a longevidade, ou mesmo o fracasso desses empreendimentos devem-se muito mais às condições exógenas, como as interferências de mercado e a relação entre a economia local e sua inserção num quadro político e econômico mais amplo - as quais em última análise regeram a dinâmica expansiva do capitalismo para as regiões de fronteira -, do que propriamente ao labor, à perseverança e à ambição daqueles que protagonizaram essas experiências históricas.

A história da colônia Varpa é de certo modo um exemplo elucidativo desse fato, pois para a escolha do local onde se realizaria a colônia, os parâmetros ditados obedeceriam não apenas a especificidades culturais e religiosas que mantivessem coeso o grupo, mas às condições econômicas e políticas de acesso à terra para os imigrantes naquele período. Tais condições devem ser levadas em conta devido à autonomia desses imigrantes, que praticamente não contaram com nenhum amparo por parte do governo brasileiro. Dentro das mesmas condições verificadas para a colonização no Oeste Paulista, o acesso à terra regeu-se quase que exclusivamente pelas flutuações da economia cafeeira e pela disponibilidade da força de trabalho, como nos faz crer Stolcke(1986); Silva(1996) e em certo sentido Font(1989), convertendo-se deste modo num elemento inibidor para qualquer política de colonização nesse estado que pudesse facilitar a pretensão dos imigrantes.

Das brechas que se abririam restavam as regiões desgastadas pela cafeicultura, resultantes do fracionamento das grandes propriedades, situadas nas regiões mais antigas, com facilidade de comunicação e próximas da capital - porém de preços mais elevados; ou as terras situadas no então extremo sertão, cujos preços eram 
mais atraentes e acessíveis aos exíguos recursos disponíveis.

Essa opção não se faria sem duras penas, pois além das inúmeras dificuldades adaptativas enfrentadas nos primeiros tempos de assentamento na região - marcados pela generalizada carência de recursos, que lhes infringiu duras perdas e incontáveis sofrimentos -, as terras adquiridas pelos colonos eram objeto de litígio entre dois grandes latifundiários que reivindicavam o direito à propriedade daquelas extensões. Custosas diligências e petições foram feitas pelos letos junto às autoridades brasileiras no sentido de resolver tais contendas, buscando a legalidade da transação por eles realizada.

Outro problema que se colocava era a questão das vias de comunicação da colônia, que, passada a fase pioneira, orientara sua produção agrícola a culturas de mercado. Tal opção estabeleceria maiores vínculos de dependência externa e a sujeição às flutuações de preços, bem como, à estandardização a padrões produtivos de mercado e à adoção de determinadas culturas, às vezes pouco adequadas às condições ecológicas da região.

A evolução econômica da colônia foi marcada por grande prosperidade material, alcançada no curto espaço de tempo que sucedeu o período pioneiro, caracterizado pelas agruras dos primeiros anos; no entanto, tal prosperidade cedo revelou sua fragilidade, diante da suscetibilidade às oscilações e incertezas de mercado e das pressões sobre as culturas implementadas, o que expunha os colonos a constantes (re)arranjos adaptativos e à adoção ou substituição de novas culturas.

\section{CONDICIONAMENTOS ADAPTATIVOS}

Por esta terminologia devemos entender toda forma de arranjo desenvolvida individual e/ou coletivamente em resposta às pressões internas ou externas causadoras de estresse ou a problemas que condicionem respostas adaptativas colocados à comunidade com vista ao estabelecimento de um padrão de vida e conforto, no mínimo, semelhante ao encontrado no país de origem. Tais respostas podem decorrer de mudanças ambientais, pressões econômicoinstitucionais e, principalmente, das oscilações de mercado.

Esta idéia nos remete necessariamente à percepção de que a condição de fronteira implica justamente, nos termos de Webb (1932), a ausência ou carência, nessas regiões recém-incorporadas à cultura ocidental, de instituições e serviços, sendo que a condição de fronteira deixa de existir quando tais carências são superadas. De modo geral compreende-se o fenômeno da fronteira em seu sentido de transitoriedade e permanente movimento, o qual designa também um período de tempo, o período de entrada dos primeiros colonos num local tido como inabitado pela cultura ocidental, independentemente das populações que nele já se encontravam ou que o haviam ocupado anteriormente.

A construção do ideário pioneiro, em seu sentido imaginário, decorre justamente desse estabelecimento e da tentativa de se construir e manter na nova terra uma comunidade, e do fato de que essas comunidades em tais regiões representavam a civilização civilização essa que era evidentemente capitalista.

Como exemplo desses condicionamentos podemos citar o fracionamento familiar, que consistiu na separação temporária de elementos das famílias em busca de trabalho fora da comunidade em formação, os quais se empregavam nas grandes fazendas de café ou em atividades urbanas, principalmente na capital do estado. Essa postura envolveu tanto homens como mulheres e fez a fama das moças letas, como exímias governantas e dedicadas domésticas entre as famílias abastadas da região da Avenida Paulista, nos anos de 1920 e 1930 . Os recursos enviados por essas pessoas representaram durante vários anos as únicas fontes seguras para a manutenção de suas famílias e a estruturação das pequenas propriedades. No caso do agrupamento comunitário da Palma, estes ingressos significaram um insumo fundamental para os investimentos que ali se concretizavam, em termos de estrutura produtiva, através da aquisição de maquinarias, ferramentas, animais, sementes, etc.

Outras estratégias adaptativas se pautaram na otimização dos recursos humanos, pois contrariamente aos dados de ingresso desses imigrantes no Brasil na categoria de trabalhadores rurais, conforme os livros de entrada da Hospedaria dos Imigrantes em São Paulo, muitos desses letos eram oriundos de ocupações urbanas, como técnicos, engenheiros, profissionais liberais, veterinários, enfermeiros, farmacêuticos, professores, artífices, escritores dentre outros setores profissionais especializados. Se tal característica pesou desfavoravelmente no início do processo de ocupação no desolador trabalho nas matas, posteriormente se converteria num trunfo para a solução criativa e inventiva dos problemas enfrentados pela comunidade e certamente no elevado padrão organizativo por eles alcançado em tão curto espaço de tempo.

Esta otimização dos recursos e do trabalho através do arranjo coletivo se converteu numa forma adaptativa bemsucedida, que assegurou, por considerável período, a estabilidade econômica e demográfica da população. Não obstante, seu limite estaria dado pela própria contradição das estruturas modernas por eles consolidadas, em sua busca de inserção na dinâmica de 
mercado, através das inúmeras atividades produtivas por eles desenvolvidas e da adoção de culturas agrícolas estandardizadas pelas demandas externas, na maioria das vezes pouco compatíveis com as condições ecossistêmicas da região.

Em que pese a isso tudo, a conformação desses arranjos apresentou resultados econômicos diferentes; pois o arranjo coletivo mostrou-se menos vulnerável às oscilações dos preços e às flutuações de mercado, devido justamente ao estilo de vida regrado e ao comportamento asceta dos membros da corporação evangélica de Palma, da mesma forma que a acentuada perda de fertilidade das terras da região foi menos sentida por este grupo, em razão das práticas agrícolas menos abusivas em relação ao uso dos solos e da adoção de técnicas agrícolas baseadas na rotatividade dos terrenos e na diversificação de culturas.

De modo geral, as constantes mudanças e a introdução de novas culturas agrícolas na região da colônia foram condicionadas por fatores exógenos, que nem sempre trouxeram resultados compensadores, mesmo entre os membros da Corporação de Palma. Em muitos casos elas levaram à estagnação das propriedades, que no final dos anos de 1940 não tinham os meios para se autofinanciar nem para manter a anterior prosperidade alcançada.

Destarte a euforia dos bons tempos foi dando lugar à resignação ante a realidade presente, caracterizada por uma visão nostálgica em relação ao passado e pela difícil jornada naquela terra prometida.

-Henrique Manoel Silva - Departamento de Educação/UEM - Universidade Estadual de Maringá/PR.

\section{REFERÊNCIAS BIBLIOGRÁFICAS}

BENNETT, John \& KOHL, Seena B.

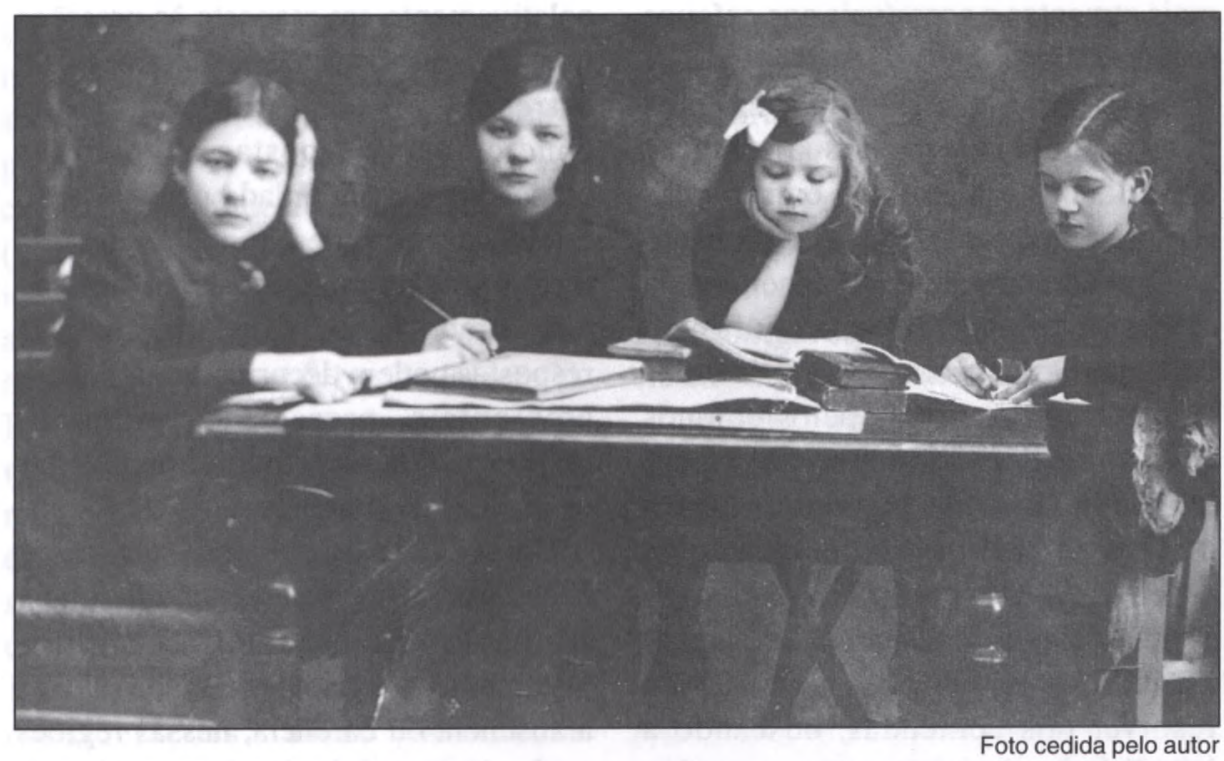

(1995) Settling the Canadian-American West, 1890 - 1915. Pioneer Adaptation and Community Building. Nebraska: University of Nebraska Press.

FONT, Mauricio

(1989) Coffee, Contention and Change. Queens College and Graduate School City. University of New York.

FRANÇA, Ary

(1976) A Marcha do Café e as Frentes Pioneiras. Rio de Janeiro: C.N.G.

INKIS, Janis

(1940) Reafirmação de Princípios. Palma(SP): Kristigs Draugs, $\mathrm{n}^{\circ} 7$ e 8.

INKIS, Janis

(1950) A vontade de Deus e os enganos na imigração da Letônia. Palma(SP): Kristigs Draugs.

MONBEIG, Pierre

(1984) Fazendeiros e Pioneiros de São Paulo. São Paulo: HUCITEC - Polis.

MONBEIG, Pierre

(1941) Algumas observações sobre Marília cidade pioneira. São Paulo: Revista do Arquivo Municipal, Departamento Cultural.

MULATINHO, Heldo Victor

(1982) Palma: A Construção de uma Utopia. 1924 - 1970. São Paulo, Tese de Doutorado apresentada ao Depto. de Antropologia Social da FFLCH USP.

OLIVEIRA, Hélio Lourenço

(1939) Relatório da Inspeção Sanitária de Tupã. (mimeo), $2^{\circ}$ semestre.

ROCHE, Jean

(1969) A Colonização Alemã no Rio
Grande do Sul. Porto Alegre: Globo. 2 vols.

RONIS, Osvaldo

(1974) Uma Epopéia de Fé. A História dos Batistas Letos no Brasil. Rio de Janeiro: Casa Publicadora Batista, pp.194-195.

SILVA, Lígia Osorio

(1996) Terras devolutas e latifúndio: efeitos da lei de 1850. Campinas: Editora da Unicamp.

STOLCKE, Verena

(1986) Cafeicultura: homens, mulheres e capital (1850 - 1980). São Paulo: Brasiliense.

SEYFERTH, Giralda

(1990) Imigração e Cultura no Brasil. Brasília: Editora UnB.

TUPES, Milia

(1979) Contribuição ao Estudo da Colonização no Estado de São Paulo. Ensaios sobre a Colônia Varpa. São Paulo, Coleção Museu Paulista. Série História, vol. 8.

VASSILIEFF, Irina

(1979) Imigração Leta no Brasil: $A$ Experiência da Colônia Varpa na Alta Paulista (1922 - 1964). Dissertação, Departamento de História - FFLCH/ USP, 249p.

WEBB, Walter $P$.

(1932) The Great Plains. New York: Ginn.

WEBER, Max

(1997) A Ética Protestante e o Espírito do Capitalismo. São Paulo: Biblioteca Pioneira de Ciências Sociais, $12^{\mathrm{a}}$ edição. 